\title{
GAIN Technology Workshops Summary Report
}

August 2016

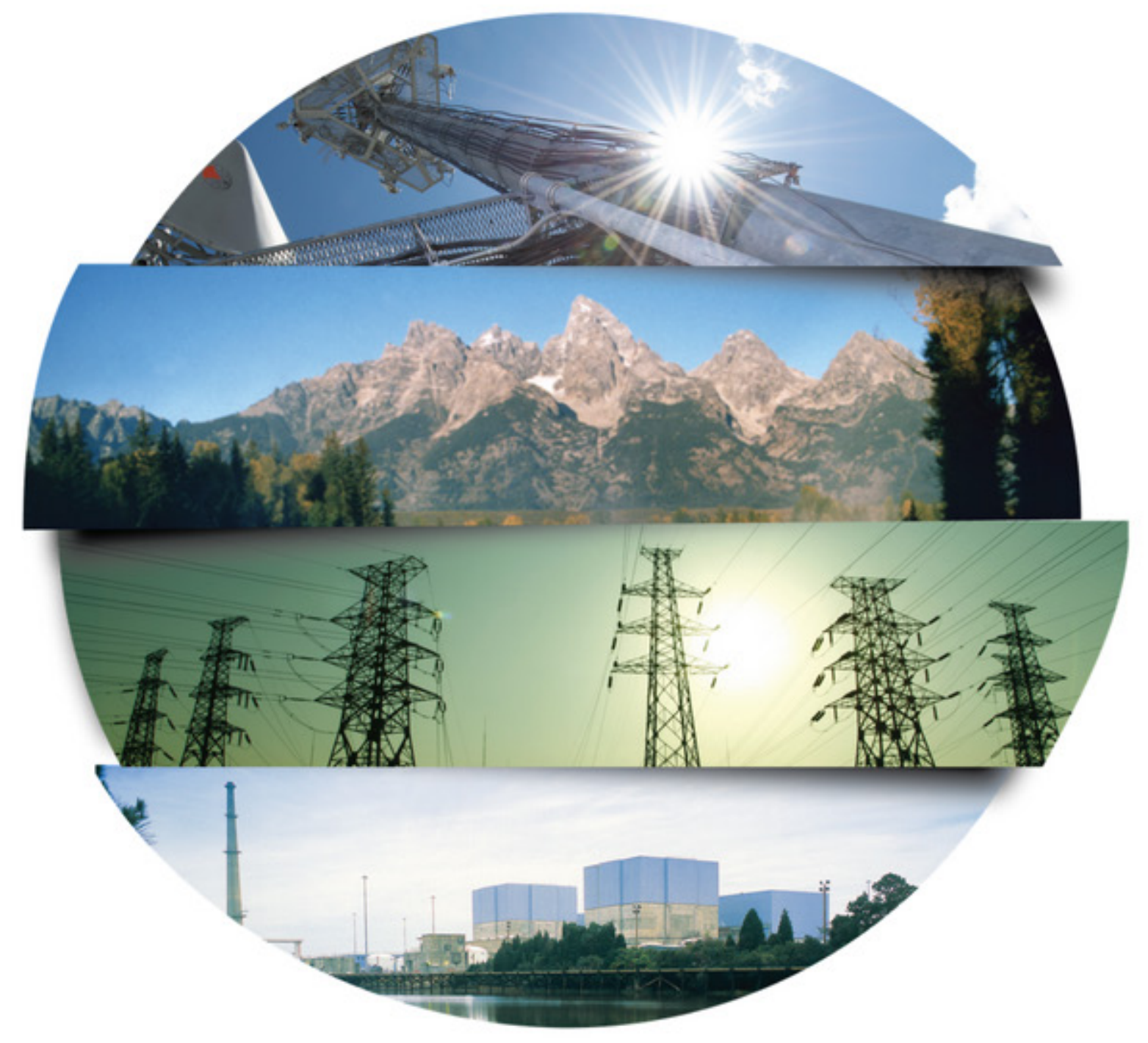




\section{GAIN Technology Workshops Summary Report August 2016}

\section{Prepared by:}

Lori Braase, GAIN Coordinator

Doug Crawford, GAIN Deputy

John Jackson, GAIN Technical Interface

Hussein Khalil, GAIN Integration Working Group Chair

\section{Approved by:}

Kemal Pasamehmetoglu, GAIN Director

Revision 1: March 24, 2017

INL/EXT-16-39732
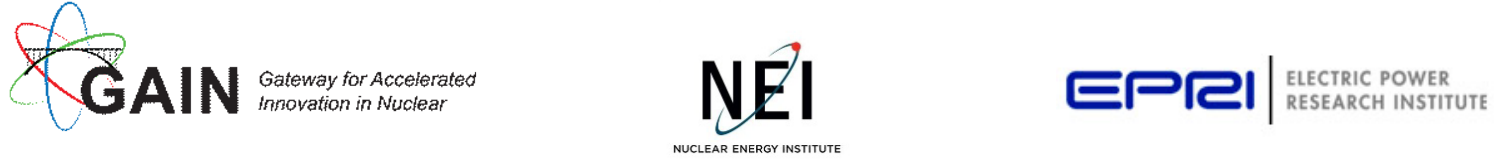

\section{DISCLAIMER}

This information was prepared as an account of work sponsored by an agency of the U.S. Government. Neither the U.S. Government nor any agency thereof, nor any of their employees, makes any warranty, expressed or implied, or assumes any legal liability or responsibility for the accuracy, completeness, or usefulness, of any information, apparatus, product, or process disclosed, or represents that its use would not infringe privately owned rights. References herein to any specific commercial product, process, or service by trade name, trade mark, manufacturer, or otherwise, does not necessarily constitute or imply its endorsement, recommendation, or favoring by the U.S. Government or any agency thereof. The views and opinions of authors expressed herein do not necessarily state or reflect those of the U.S. Government or any agency thereof. 


\section{EXECUTIVE SUMMARY}

The Gateway for Accelerated Innovation in Nuclear (GAIN) initiative, the Nuclear Energy Institute (NEI), and the Electric Power Research Institute (EPRI) hosted three technologyspecific workshops to discuss the research, development, and demonstration (RD\&D) needs of industries targeting advanced nuclear energy technologies. These workshops, held in July 2016, engaged companies developing concepts in Molten Salt Reactor, High Temperature Gas Reactor, and Fast Reactor Technologies. Participants from these advanced reactor design communities were asked to present their RD\&D needs for design and licensing that the Department of Energy Office of Nuclear Energy (DOE-NE) is uniquely qualified to address.

The results of each workshop form the basis for recommendations to DOE to be incorporated into the base RD\&D programs in the upcoming years. By focusing on the needs that can benefit multiple designs in a given technology area, the identified needs will be used to streamline the DOE-NE RD\&D programs commensurate with the funding availability.

Resulting from interest expressed during the workshops, two industry-led, technology-specific working groups (TWG) were established for the molten salt reactor (MSR) and the fast reactor communities. The working groups are established to identify and collaborate on technologyspecific issues, recommend course corrections, and rapidly transfer progress to design decisions. NEI has agreed to facilitate the activities of the newly formed working groups. The input from the working groups along with the initial RD\&D needs identified during the workshops will be valuable in formulating the annual work-scope for the base RD\&D programs.

Given that the fiscal year (FY) 2017 budget is already constrained, not all the new activities can be initiated immediately. The high-priority recommendations for DOE to consider as part of the base programs in FY 2017 are summarized below. These were areas of interest to the participants of all three workshops.

1. Access to applied technology (AT) documents. DOE is reviewing options to facilitate access by U.S. commercial organizations to AT documents on advanced reactor and fuel technologies.

- Create a list of AT-marked documents available once access requirements are met

- Clarify the access requirements

- Remove the AT designation on high-demand documents (after the proper review).

2. M\&S code development and validation for design and licensing. EPRI will engage with subject matter experts and stakeholders in the near future to define gaps in this area and to coordinate efforts to address the identified needs. A common paradigm will be targeted for meeting the NRC's validation requirements and need for confirmatory codes.

- Support the EPRI-led M\&S workshops

- Provide a description and status of DOE-NE's advanced M\&S tools 
- Develop plans for additional code development to address gaps

- Develop a joint-strategy with the stakeholders for the verification and validation (V\&V) of advanced tools, including cross-cutting and design specific issues

- Develop a joint strategy with the Nuclear Regulatory Commission (NRC) for V\&V and usage of advanced tools for licensing analyses.

3. Advanced reactors licensing framework. Accelerate the joint work with NRC for the advanced reactor licensing strategy including

- General design criteria

- Gradual reduction of licensing risk

- Risk-informed and performance-based licensing strategy.

4. Capability to employ fuels with uranium enriched to greater than $5 \%$ (up to $20 \%$ ). This is a need for multiple advanced reactor designs, including most of the designs considered during the workshop. NEI will work with industry, DOE, and NRC to understand needs and issues from industry, as well as the regulatory and policy issues associated with obtaining, in the near-term and long-term, uranium enriched above 5\% and below $20 \%$.

In addition to these cross-cutting needs for all of the technologies, a few design-specific, highpriority recommendations are provided below.

- The MSR community identified a set of needs for the fundamental data and multiple small-scale test loops as discussed in the report. For FY 2017, a feasibility assessment of a small-scale molten-salt loop with dissolved fuel is a high priority initial step. The recommendations are

- Perform a feasibility assessment for a megawatt scale, molten-salt fueled critical system to be tested at a DOE site

- Identify alternatives to critical-system demonstration for meeting all the identified data-needs using different and simpler options.

- The specific RD\&D needs are different in the fast reactor community depending on the coolant (sodium, lead, or gas). Access to fast spectrum testing capabilities is a common, high-priority need, which is currently only available in Russia. For FY 2017, the recommendations are

- Complete the options and requirements assessment for a domestic fast spectrum test reactor

- If the need and feasibility are validated, complete the mission need (Critical Decision, CD-0).

- The high-temperature gas reactor community identified the completion of the TRISO fuel and graphite qualification program as the high-priority need. That effort is on-going within DOE-NE's base program. 


\section{TABLE OF CONTENTS}

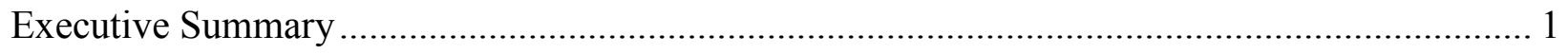

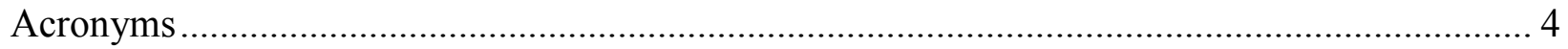

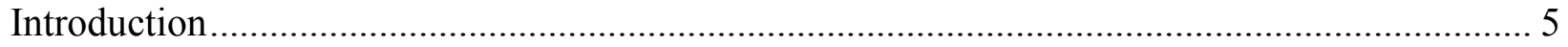

Workshop Overview …………………………………….............................................. 7

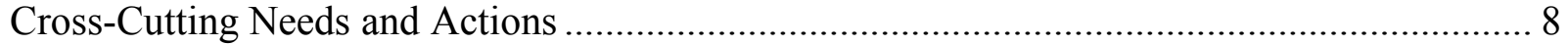

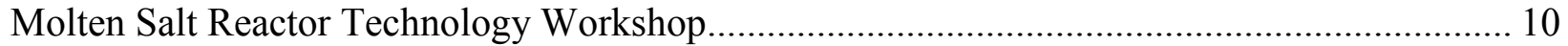

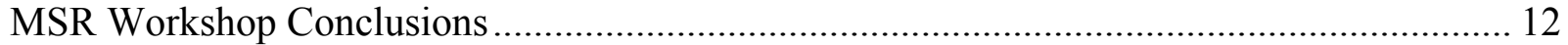

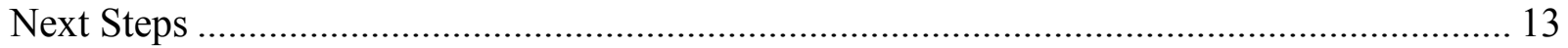

High Temperature Gas Reactor Technology Workshop.............................................................. 14

HTGR Workshop Conclusions .................................................................................... 15

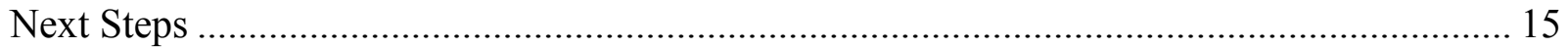

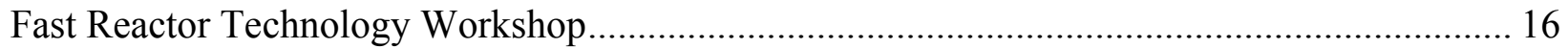

Fast Reactor Workshop Conclusions ………………….................................................. 20

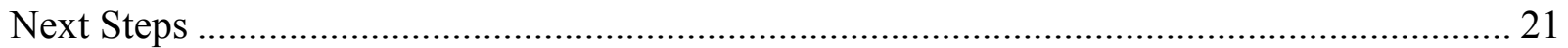




\section{ACRONYMS}

AGR Advanced Gas Reactor

ANL Argonne National Laboratory

ARWG Advanced Reactor Working Group

AT applied technology

BWXT Babcock and Wilcox Technologies

DOE-NE Department of Energy Office of Nuclear Energy

EBR Experimental Breeder Reactor

EPRI Electric Power Research Institute

FY fiscal year

GAIN Gateway for Accelerated Innovation in Nuclear

HTGR high temperature gas reactor

INL Idaho National Laboratory

IP Intellectual property

LEU low enriched uranium

LWR light water reactor

M\&S modeling and simulation

MSR molten salt reactor

NEI Nuclear Energy Institute

NGNP Next Generation Nuclear Plant

NRC Nuclear Regulatory Commission

ORNL Oak Ridge National Laboratory

RD\&D research, development, and demonstration

RDD\&D research, development, demonstration, and deployment

TRL technology readiness level

TWG technology working group

U.S. United States

$\mathrm{V} \& \mathrm{~V} \quad$ verification and validation 


\section{INTRODUCTION}

National and global demand for nuclear energy is increasing and United States (U.S.) global leadership is eroding. There is a sense of urgency with respect to the deployment of innovative nuclear energy technologies. The Gateway for Accelerated Innovation in Nuclear (GAIN) initiative is based on the simultaneous achievement of three strategic goals. The first is the U.S. Department of Energy (DOE) objective to maintain global technology leadership in nuclear energy. The second is enabling global industrial leadership for nuclear vendors and suppliers. The third is focused on utility optimization of nuclear

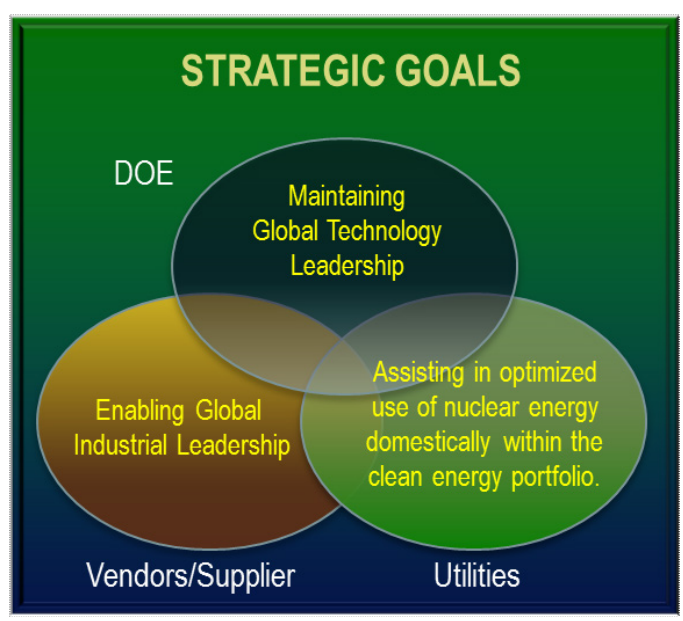
energy within the clean energy portfolio. An effective public-private partnership is required to achieve these goals.

GAIN is a public-private partnership and the organizing principle for the relevant Department of Energy Office of Nuclear Energy (DOE-NE) programs. GAIN's mission is to provide the nuclear energy industry with access to technical, regulatory, and financial support necessary to move innovative nuclear energy technologies toward commercialization in an accelerated and costeffective fashion. ${ }^{1}$

DOE recognizes the recent sense of urgency for new developers and investors in getting concepts to market. It is understood that time-to-market for nuclear technology is excessive and the facilities needed to conduct RD\&D activities are very expensive to develop and maintain. For reactor technologies at lower technology readiness levels (TRL), materials testing, analysis, modeling, code development, etc., are needed, most of which can be met currently in the DOE national laboratory system. However, mature technologies typically need large, dedicated component testing and demonstration facilities, which are expensive and require long-lead time. Figure 1 shows this comparison in the development cycle.

A primary purpose of the regulatory support portion of the GAIN initiative is to increase the "licensing readiness level" of various advanced reactor technologies. Overall, "readiness" is established and confirmed by considering and addressing key parts of the licensing process, including:

\footnotetext{
${ }^{1}$ INL/EXT-16-39715, GAIN Execution Plan, August 2016.
} 
- Implementing policy and regulatory adaptations to the current set of light water reactor (LWR)-based regulatory and licensing technical review requirements to focus on advanced technologies.

- Identifying and addressing the high-priority research and technical development activities that are critical to establishing advanced reactor safety bases and satisfying licensing technical requirements derived from the adapted regulatory requirements.

- Establishing the potential for use of incremental or "staged" regulatory reviews to achieve early feedback from the regulator in areas of specific technical risk or uncertainty.

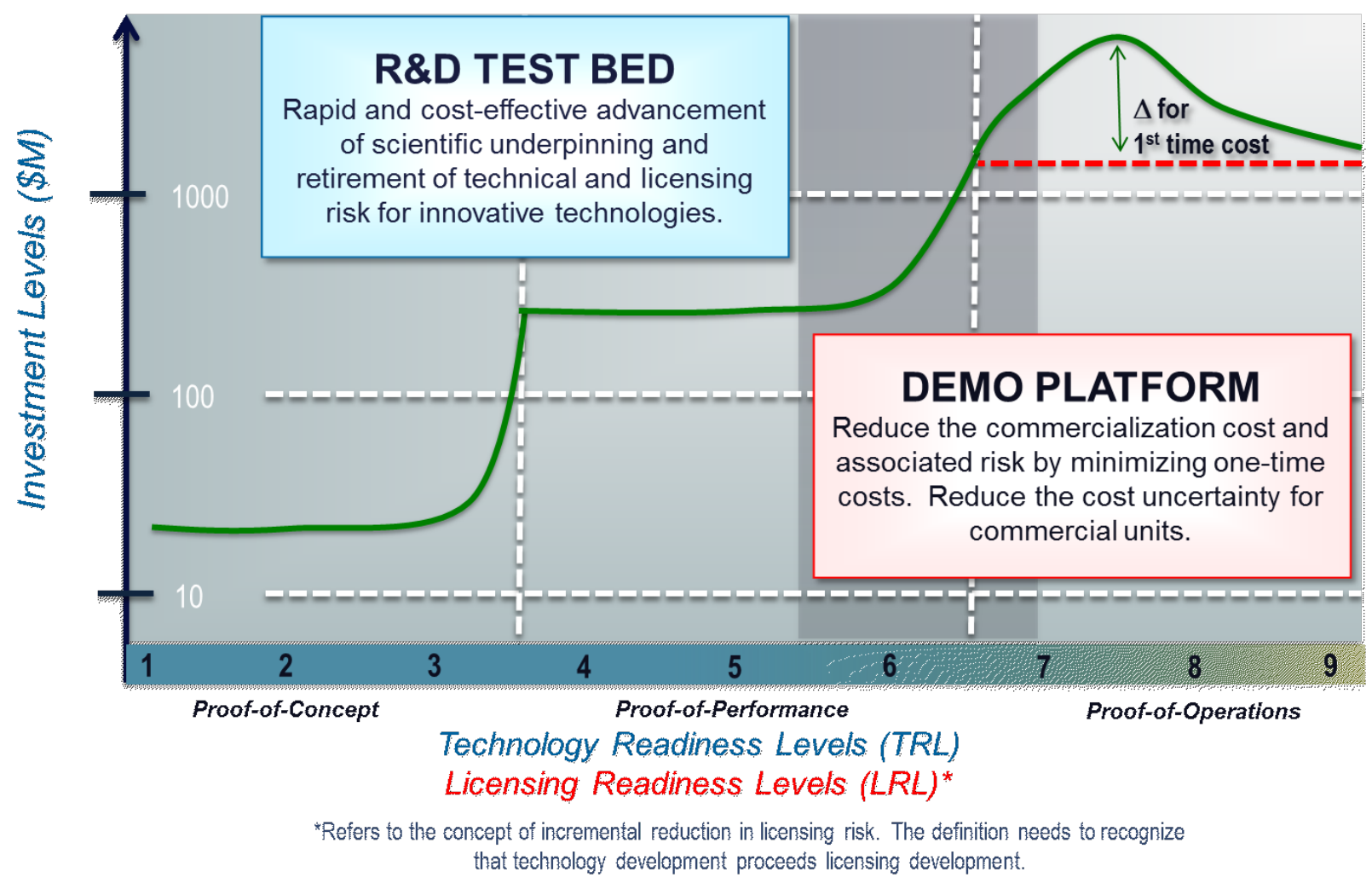

Figure 1. Major investment and risk for advanced reactor technology developers.

By understanding the needs of advanced nuclear technology developers, GAIN will facilitate access to DOE national laboratory capabilities (e.g., facilities, expertise, materials, and data) to meet industry RD\&D needs. In addition, GAIN is working with NRC to streamline processes and increase understanding of the licensing requirements for advanced reactors. 


\section{Workshop Overview}

As a means of establishing an initial understanding of technical issues that DOE is uniquely suited to address, GAIN, NEI, and EPRI hosted technology-specific workshops to discuss RD\&D needs of industries targeting advanced nuclear energy technologies. These workshops, held in July 2016, engaged companies developing concepts in molten salt reactor, high temperature gas reactor (HTGR), and fast reactor technologies (Table 1). Participants from these advanced reactor design communities were asked to present their RD\&D needs in the following areas:

- General concept overview

- Technology commercialization strategy; demonstration reactor versus pilot scale versus first-of-a-kind

- Schedule constraints and critical path items

- $\quad R D \& D$ needs; not necessarily design specific, but generic in nature (e.g., modeling and simulation, test loops)

- Infrastructure gaps; major missing infrastructure that requires substantial investment and time

- Licensing support, such as safety analysis tools and licensing strategies

- Recommendations on contracting and collaboration mechanisms with DOE.

The results of each workshop formed the basis of a set of recommendations to DOE to be incorporated into the base RD\&D programs. Resulting from interest expressed during the workshops, two industry-led TWGs were established. The MSR TWG and the Fast Reactor TWG were established to identify and collaborate on technology-specific issues, recommend course corrections, and rapidly transfer progress to design decisions.

Table 1. Workshop participants and technology areas.

\begin{tabular}{|c|c|c|}
\hline $\begin{array}{c}\text { Molten Salt Reactor Technology } \\
\text { Workshop } \\
\text { July 11-12, } 2016 \\
\text { EPRI Offices }\end{array}$ & $\begin{array}{l}\text { High Temperature Gas Reactor } \\
\text { Technology Workshop } \\
\text { July 14, } 2016 \\
\text { NEl Offices }\end{array}$ & $\begin{array}{l}\text { Fast Reactor Technology } \\
\text { Workshop } \\
\text { July 21-22, } 2016 \\
\text { NEI Offices }\end{array}$ \\
\hline $\begin{array}{c}\text { Elysium Industries } \\
\text { Flibe Energy } \\
\text { Southern Co. } \\
\text { Southern Co. / TerraPower LLC } \\
\text { Terrestrial Energy USA } \\
\text { Transatomic }\end{array}$ & $\begin{array}{c}\text { AREVA } \\
\text { General Atomics } \\
\text { X-Energy }\end{array}$ & $\begin{array}{c}\text { Advanced Reactor Concepts } \\
\text { General Atomics } \\
\text { GE-Hitachi Nuclear Energy } \\
\text { Oklo } \\
\text { Westinghouse }\end{array}$ \\
\hline
\end{tabular}

Industry representatives attending the workshops all identified the currently ongoing DOE-NRC joint initiative to create non-LWR design criteria as an area that both DOE and industry should continue to support through completion of NRC's formal issuance of its regulatory guide 
planned for 2017. Attendees also summarized the following three areas where increased access and interactions with the national laboratory complex could significantly increase the licensing readiness levels of these technologies, by allowing developers to be better able to discuss and defend the respective advanced reactor technologies and the associated safety cases of their individual reactor facility designs. In each of these three areas, industry representatives and NRC observers also confirmed the need for early interaction with the NRC staff to establish plans for validation, while maintaining adequate levels of independence.

1. Codes and methods development support

- Coupling of neutronics and thermal-hydraulics codes

- Characterization of fission product transport from fuel to the environment.

2. Support for establishing a path to fuel qualification

- Continuation of DOE's support to the Advanced Gas Reactor (AGR) Program for a modular HTGR

- Increased access to historical fuel testing data in support of MSRs and fast reactors.

3. Development of modeling and simulation tools that can potentially reduce testing and experiment scope, while still satisfying NRC license application review requirements.

In general, all indicated that the establishment of a "staged" NRC review process would be a very impactful process change supporting advanced technology development and deployment.

\section{Cross-Cutting Needs and Actions}

During each of the technology specific workshops, the GAIN team compiled a summary list of R\&D needs and suggestions cited by the workshop participants. These summary lists were used as a basis for discussion in closing sessions with an emphasis on consideration of R\&D needs that could be addressed only with DOE involvement and support. Additionally, means to facilitate public-private partnerships (e.g., contracting with DOE) were extensively discussed, and workshop participants identified activities that could help commercial organizations pursuing all three types of technology.

The following needs were identified in all three technology workshops and initial actions to address these needs were determined. As these actions are completed and the needs evolve, status information will be provided to the appropriate TWGs during meetings or by other forms of electronic communication. 
1. Access to applied technology (AT) documents. DOE is reviewing options to facilitate access by U.S. commercial organizations to AT documents on advanced reactor and fuel technologies.

- Create a list of AT-marked documents available once access requirements are met

- Clarify the access requirements

- Remove the AT designation on high-demand documents (after the proper review).

2. M\&S code development and validation for design and licensing. EPRI will engage with subject matter experts and stakeholders in the near future to define gaps in this area and to coordinate efforts to address the identified needs. A common paradigm will be targeted for meeting the NRC's validation requirements and need for confirmatory codes.

- Support the EPRI-led M\&S workshops

- Provide a description and status of DOE-NE's advanced M\&S tools

- Develop plans for additional code development to address gaps

- Develop a joint-strategy with the stakeholders for the verification and validation (V\&V) of advanced tools, including cross-cutting and design specific issues

- Develop a joint strategy with the Nuclear Regulatory Commission (NRC) for V\&V and usage of advanced tools for licensing analyses.

3. Advanced reactors licensing framework. Accelerate the joint work with NRC for the advanced reactor licensing strategy including:

- General design criteria

- Gradual reduction of licensing risk

- Risk-informed and performance-based licensing strategy.

4. Capability to employ fuels with uranium enriched to greater than $5 \%$ (up to $20 \%$ ). This is a need for multiple advanced reactor designs, including most of the designs considered during the workshop. NEI will work with industry, DOE, and NRC to understand needs and issues from industry, as well as the regulatory and policy issues associated with obtaining, in the near-term and long-term, uranium enriched above 5\% and below $20 \%$.

NEI will facilitate the activities of the newly formed working groups for molten salt and fast reactors. NEI will coordinate their activities with those of the NEI Advanced Reactor Working Group (ARWG). NEI will also coordinate with GAIN and EPRI to support the efforts of the working groups. EPRI and NEI are partners in GAIN and made key contributions to the organization and conduct of the three workshops. GAIN, EPRI, and NEI will continue to communicate and work together closely to build on the success of the workshops with the goal of accelerating the commercial availability and deployment of advanced reactors.

Each technology workshop is summarized in the sections below. For questions or additional information, please contact Lori Braase, lori.braase@,inl.gov. 


\section{MOLTEN SALT REACTOR TECHNOLOGY WORKSHOP}

The MSR Technology Workshop was held on July 11-12, 2016, at the EPRI offices in Washington D.C. Represented companies included Elysium Industries, Flibe Energy, Southern Company/TerraPower LLC, Southern Company Services, Terrestrial Energy, USA, and Transatomic Power Corporation. In addition, representatives attended from NRC, DOE, EPRI, NEI, Argonne National Laboratory (ANL), Idaho National Laboratory (INL), and Oak Ridge National Laboratory (ORNL).

Shane Johnson, Deputy Assistant Secretary, DOE-NE, Andrew Sowder, EPRI, and Everett Redmond, NEI, welcomed the participants and stated the importance of this meeting to GAIN and to the nation's energy goals. Kemal Pasamehmetoglu, GAIN Director, provided an overview of GAIN and the importance of advanced reactor community input in associated capability development at DOE national laboratories. The lunch presentation by David Holcomb, ORNL, offered an overview of current and past DOE research activities in molten salt.

Each of the six private-sector participants presented an overview of their technology concept and associated development needs. On the second day, industry participants discussed their combined list of research needs that DOE should pursue or develop in support of molten salt reactor technology development and commercialization (see Table 2).

Table 2. Molten salt reactor technology RD\&D support needs.

\begin{tabular}{|c|l|}
\hline$\#$ & Molten Salt Reactor Technology RD\&D Support Needs (in no particular order) \\
\hline 1 & Test loops for T-H and materials tests \\
\hline 2 & Multi-physics modeling and simulation (including safety analysis) \\
\hline 3 & Fundamental data/physical properties \\
\hline 4 & Irradiation testing \\
\hline 5 & Reactor physics - cross sections and critical experiments \\
\hline 6 & Catalog of legacy MSR information/knowledge \\
\hline 7 & Policy related (e.g., research-reactor power limit (1 versus 10 MW)) \\
\hline 8 & Regulatory framework / licensing support \\
\hline 9 & Fuel cycle issues (processes/infrastructure/safeguards) \\
\hline 10 & Instrumentation and controls \\
\hline 11 & Primary salt chemistry and control \\
\hline 12 & Materials data and code cases \\
\hline 13 & Waste Forms and management options \\
\hline 14 & Advanced power conversion cycles \\
\hline 15 & Streamlined contracting with DOE national laboratories \\
\hline
\end{tabular}


Additional detail on the needs listed in Table 2 is summarized below.

1. Molten salt test loops

- Different sizes, salt compositions and testing capabilities

- Enable testing of seals, welding materials, and instrumentation

- Assess corrosion and other mechanisms of materials degradation.

2. Multi-physics and multi-scale modeling

- Coupled neutronics, thermal-hydraulics, and structural models

- Simulation of flowing fuels for design and safety analysis

- Safety analysis tools and validation data to support license applications to NRC.

3. Fundamental data and properties for molten salts bearing actinides and fission products

- Thermal-hydraulic

- Thermo-physical

- Thermo-chemical, including solubility of salt constituents

- Possible approach is to develop and benchmark capabilities to measure properties. When confident in their applicability and uncertainties, etc., make the capabilities available for design-specific measurements.

4. Irradiation testing

- Salt and materials in capsules

- Molten salt irradiation test loops.

5. Reactor physics data

- Cross-section measurements to address gaps in nuclear data (ENDF/B files)

- Critical experiments to benchmark codes.

6. MSR data, reports, and knowledge

- Provide access to AT

- Identify and catalogue the data.

7. Policy

- Request licensing accommodation for 10-megawatt, liquid-fueled test reactor, rather than the current 1-megawatt limit for research reactors

- Request allowance for greater than $50 \%$ cost recovery limit for a test reactor

8. Regulatory framework

- Emphasis here on activities not being worked from the NEI Advanced Reactor

Regulatory Task Force

- Fuel qualification guidelines

- Transportation issues for fuel feedstocks and waste forms 
9. Fuel cycle related issues

- Uranium enrichment considerations, including potential down-blending to $19.75 \%{ }^{235} \mathrm{U}$ enrichment

- Strategies for chemical form and enrichment of uranium feedstock

- Safeguards, including material control and accountability

- Storage of molten salt and waste forms.

10. Instrumentation and control

- Salt chemistry/composition sensors

- Radiation hardened sensors for diverse measurements in molten salt environment.

11. Primary salt chemistry control and management

- Fission product management (insoluble, soluble, gas sparging, salt polishing)

- Time-dependent and temperature-dependent salt chemical behavior

- Tritium removal.

12. Materials data and code cases.

13. Ultimate waste forms (fund property analysis).

14. Advanced power conversion and heat rejection systems

- Air and water

- $\mathrm{SCO}_{2}$ power conversion.

15. Streamlined contracting with DOE national laboratories.

\section{MSR Workshop Conclusions}

From the topics listed in the previous section, the following were determined by consensus of the participants to be worthy of priority consideration for inclusion in DOE-NE's RD\&D program. These tasks were prioritized because they can be performed only at DOE national laboratories, or because other expertise (e.g., at universities) available through DOE-NE is particularly wellsuited for the work. In addition, the selected topics are those that could be undertaken with some beneficial impact during FY 2017 and 2018.

- Identification and cataloging of data, reports, and knowledge

- Facilitate access to AT information, including listings of available AT documents

- Development of a multi-physics, multi-scale analysis tool package within 12 to 18 months for subsequent analysis of and benchmarking for specific systems

- Fundamental properties determination

- Thermo-physical, thermo-chemical

- Neutron cross section measurements 
- A flowing molten salt loop that could be incorporated into a test reactor to validate knowledge of molten salt properties and reduce associated uncertainties

- Streamlined contracting with DOE national laboratories.

\section{Next Steps}

1. The participants proposed to form an industry-led MSR TWG, supported by the NEI ARWG, EPRI, and GAIN. Near-term actions are listed below:

- The next meeting of participants will be as the newly-formed MSR TWG

- The first meeting is scheduled for September 7,2016 at the NEI Offices, Washington DC

- The second meeting is set for October 3, 2016 at ORNL in conjunction with the ORNL MSR Technology Workshop (October 4-5, 2016)

- A draft working group structure and charter will be prepared and distributed for discussion at that meeting

- The status and requirements of a small-scale molten-salt loop with dissolved fuel.

- The MSR TWG chair will be invited to participate on the GAIN Integration Working Group (IWG).

2. GAIN will prepare a feasibility assessment for a megawatt scale, molten-salt fueled critical system to be tested at a DOE site. The study will evaluate the feasibility of building and operating the system for validation of MSR fundamental data and modeling tools; testing of materials, instruments, and diagnostics; and proof-of-principle verification of MSR technology under conditions of interest for industry developers. In addition, alternatives to critical-system demonstration will be identified to meet the data needs using different and simpler options. 


\section{HIGH TEMPERATURE GAS REACTOR TECHNOLOGY WORKSHOP}

The HTGR Workshop was held on July 14, 2016, at the NEI offices in Washington, DC. Represented companies included AREVA, General Atomics, and X-Energy. In addition, representatives attended from NRC, DOE-NE, EPRI, NEI, ANL, INL, and ORNL.

Mike Worley, DOE-NE, Tina Taylor, EPRI, and Everett Redmond, NEI, welcomed the participants and stated the importance of this meeting to GAIN and to the nation's energy goals. Kemal Pasamehmetoglu, GAIN Director, provided an overview of GAIN and discussed two major decisions points involving early technology feasibility and testing and later-stage, highinvestment demonstration. The lunch presentation by Hans Gougar, INL, reviewed the long history of HTGR development in the U.S. and provided a short status of current and DOE research activities in these systems.

Each of the three private-sector participants presented an overview of their technology concept and associated development needs. A combined list of research needs was compiled and discussed, with a focus on what DOE should pursue or develop in support of HTGR technology development and commercialization (see Table 3).

Table 3. High temperature gas reactor technology RD\&D support needs.

\begin{tabular}{|c|l|}
\hline$\#$ & High Temperature Gas Reactor Technology RD\&D Support Needs (in no particular order) \\
\hline 1 & Continue DOE'S RD\&D effort in support of HTGR (e.g., validation of passive cooling) \\
\hline 2 & $\begin{array}{l}\text { M\&S (e.g., core neutronics and thermal hydraulics, fuel performance, fission product release } \\
\text { and transport, multi-physics modeling, fuel qualification codes and methods) }\end{array}$ \\
\hline 3 & $\begin{array}{l}\text { Maintain domestic nuclear fuel fabrication capability in the interim with Babcock and Wilcox } \\
\text { Technologies (BWXT) }\end{array}$ \\
\hline 4 & NRC engagement to enable licensing of a demonstration unit by 2030 \\
\hline 5 & $\begin{array}{l}\text { Low enriched uranium (LEU) supply chain }\left({ }^{235} \mathrm{U} \text { enrichment greater than } 5 \% \text { will be needed }\right. \\
\text { for future advanced reactors) }\end{array}$ \\
\hline 6 & Power conversion system testing \\
\hline 7 & Gas turbine testing \\
\hline
\end{tabular}

Additional detail on the needs listed in Table 3 is summarized below.

1. Continue DOE's RD\&D effort in support of HTGR (e.g., passive cooling)

- DOE Next Generation Nuclear Plant (NGNP) investments for TRISO fuel and graphite qualifications are critical path technologies

- Commercial organization access to DOE sites to accelerate advanced reactor deployment

- Full scale demonstration reactor at a DOE site

- HTGR fuel testing in the INL's Advanced Test Reactor (under the AGR program) will conclude in 2019. Industry will be interested in the results. 
2. Modeling and simulation

- Core neutronics and thermal hydraulics

- Fuel performance

- Fission product release and transport

- Multi-physics modeling

- Fuel qualification codes and methods

- Probabilistic risk assessment

- High performance computing.

3. Maintain domestic nuclear fuel fabrication capability in the interim with BWXT

- DOE could help preserve/retain the BWXT fuel work scope, which ends in 2016.

4. NRC engagement to enable licensing of a demonstration unit by 2030

- NRC licensing process should be updated to better accommodate new technologies and concepts (non-LWRs)

- Costs of NRC engagements and pre-application/application reviews are excessive for a new commercial nuclear technology provider.

5. LEU supply chain $\left({ }^{235} \mathrm{U}\right.$ enrichment greater than $5 \%$ will be needed for advanced reactors).

6. Power conversion system testing.

7. Gas turbine testing.

\section{HTGR Workshop Conclusions}

In general, commercial HTGR companies agree that they do not need additional technology development assistance from DOE at this time. They strongly supported the current RD\&D efforts in support of HTGR (e.g., passive cooling validation). In addition, DOE/NGNP investments for TRISO fuel and graphite qualifications are seen as critical path technologies. As a means of accelerating the commercial deployment of HTGR technology, industry representatives expressed interest in gaining future access to DOE sites for siting a test reactor or a full scale demonstration HTGR.

\section{Next Steps}

Recognizing the strong interest and challenges in code development and validation for design and licensing, EPRI will engage with subject matter experts and stakeholders in the near future to define gaps in this area and to coordinate efforts to address the identified needs. A common paradigm will be targeted with other (non-HTGR) reactor technologies on how the need for confirmatory codes will be handled by NRC. 


\section{FAST REACTOR TECHNOLOGY WORKSHOP}

The Fast Reactor Technology Workshop was held on July 21-22, 2016, at NEI offices in Washington, DC. Represented companies included Advanced Reactor Concepts (ARC), General Atomics (GA), General Electric-Hitachi (GEH), Oklo, and Westinghouse. In addition, representatives attended from NRC, DOE-NE, EPRI, NEI, ANL, INL, and ORNL

Shane Johnson, DOE-NE, Tina Taylor, EPRI, and Everett Redmond, NEI, welcomed the participants and pointed out the importance of this meeting to GAIN and to the nation's energy goals. Kemal Pasamehmetoglu, GAIN Director, provided an overview of GAIN and discussed two major decisions points involving early technology feasibility and testing and later-stage, high investment demonstration. The lunch presentation by Bob Hill, ANL, reviewed the history of fast reactor development in the U.S. and provided a short status of current and DOE research activities in these systems.

Each of the five private-sector participants presented an overview of their technology concept and associated development needs. A combined list of research needs was compiled and discussed, with a focus on what DOE should pursue or develop in support of Fast Reactor technology development (see Table 4).

Table 4. Fast reactor technology RD\&D support needs.

\begin{tabular}{|c|l|}
\hline$\#$ & Fast Reactor Technology RD\&D Support Needs (in no particular order) \\
\hline 1 & Fast test reactor \\
\hline 2 & $\begin{array}{l}\text { Sensors and instrumentation for monitoring and inspecting in high-temperatures in opaque } \\
\text { coolants }\end{array}$ \\
\hline 3 & M\&S and analysis tools for early concept design through NRC licensing \\
\hline 4 & Advanced fuel/cladding development \\
\hline 5 & $\begin{array}{l}\text { Uranium enrichment }>5 \% \text { (availability of uranium feedstock, licensing of fabrication facilities } \\
\text { and transportation casks) }\end{array}$ \\
\hline 6 & Fuel Fabrication Center at a national lab \\
\hline 7 & Decay heat removal and component test facilities \\
\hline 8 & $\begin{array}{l}\text { Access to AT documents for better and quicker access to fuel and EBR-II testing data, } \\
\text { especially AT information }\end{array}$ \\
\hline 9 & Mechanistic source term development \\
\hline 10 & Licensing approach and data needs \\
\hline 11 & Access to historical data (EBR-II) \\
\hline 12 & Materials testing (e.g., SiC-SiC, other high temperature materials) \\
\hline 13 & Fuel transient testing \\
\hline 14 & Fuel performance testing and data \\
\hline 15 & Nuclear engineers; increase staff in nuclear energy industry \\
\hline 16 & Staff exchange/rotation between industry and labs \\
\hline 17 & Standardized contracting \\
\hline
\end{tabular}




\begin{tabular}{|c|l|}
\hline$\#$ & Fast Reactor Technology RD\&D Support Needs (in no particular order) \\
\hline 18 & Cost of doing business at DOE laboratories \\
\hline 19 & Start doing something now \\
\hline
\end{tabular}

Additional detail on the needs listed in Table 4 is summarized below.

1. Fast test reactor

- New technology testing

- Continued optimization of more mature technology

- Qualify materials and fuels

- Very high neutron flux

- Provided with test loops for reproducing technology-specific (GFR, LFR, and MSR) operating conditions in terms of type of coolant (helium, lead, and molten salts), neutron flux and spectrum, temperature and, when important, coolant flow and its chemistry.

- The lack of a fast neutron test facility forces the advanced reactor industry to look overseas to perform neutron irradiations. While testing at foreign fast reactors is possible, it is often difficult and the contracting process is slow. If the U.S. is to remain a key player in the development and deployment of advanced reactors, a fast spectrum test facility will be needed.

2. Sensors and instrumentation for monitoring and inspecting in high-temperature, opaque coolants

- Monitor neutron environments

- Monitoring of reactor operating conditions

- Analysis techniques for sensor data.

3. M\&S and analysis tools

- For different uses and stages of reactor development

- Early concept design through NRC licensing

- Reduced-order (simplified modeling) capability and multiple configurations with rapid design change capability to test feasibility

- Codes and methods to support design and to extrapolate to new operating conditions. Verified and validated open source applications that can be applied or adapted to do proprietary analysis

- For use by commercial organizations and NRC

- NRC (confirmatory use)

- Industry (codes and methods usable by industry, with appropriate V\&V and pedigree).

- For DOE and national laboratory roles

- Improve modeling capabilities, facilitate their use, and streamline access to the tools

- Provide technology developers training opportunities now so they can better identify their need for M\&S and for analysis tools

- Provide access to high-performance computing resources, including hardware. 
- For different reactor systems and phenomena

- Simulations of materials performance

- Multi-physics modeling of reactor and fuel behavior, including radiation damage

- Fuel burnup model to develop and validate depletion codes for long-burn operations

- V\&V of tools for design development and safety analysis

4. Advanced fuel and cladding development

- Continue current DOE fuel and cladding development as planned

- Collaborate with industry to understand their concepts

- Better access to existing data within DOE and its laboratories

- Fuel database for licensing with pedigree.

- Out-of-reactor cladding corrosion testing capabilities for various coolants

- Research on uranium nitride fuel.

5. Enable use of enrichment $>5 \%$ (up to $20 \%$ )

- Material availability of 20-50 metric tons will be needed soon

- Transportation casks and licensing

- Regulatory issues for enrichment $>5 \%$

- NEI working group will be initiated

- Consider discontinuing (or delaying) the current down-blending of highly-enriched uranium.

6. Fuel Fabrication Center at a national laboratory

- Multi-fuel fabrication capability

○ Proof of process

- Test fuel fabrication capability

- Fabrication process development and scale-up

- Produce initial core loadings, prior to establishment of commercial fabrication

- Provide contracted fuel fabrication under a NQA-1 Program. A commercial metal fuel vendor does not exist in the U.S.

7. Decay heat removal and component test facilities

- Support general technology development

- Similar to the ANL shutdown heat removal test facility

- Access to DOE lab facilities for component testing

- Innovative heat exchanger design and testing

- Consider a working group to identify the requirements and planning for what is needed for component testing. DOE expertise could be useful even if we use other facilities and private options.

8. Access to AT documents for better and quicker access to fuel and EBR-II testing data, especially the AT information

- Same day easy access and group access is needed 
- DOE is exploring the possibility of removing the AT label.

9. Mechanistic source term development

- This is a critical need for regulatory review of advanced reactors

- Potential application for operating conditions, design-basis events and beyond-designbasis events

- Consequence analysis to inform design and emergency planning

- Help in defining mechanistic source term approach/methodology, which should be applicable to all advanced reactor types. (It is the implementation that would depend on the particular reactor technology and fuel.)

- Continue DOE source term efforts already underway and plan next steps.

10. Licensing approach and data needs

- The Fast Reactor TWG to discuss approaches

- Code development and validation for design and licensing

- NEI, EPRI, DOE, NRC - all working on this item.

11. Access to historical data, including operating procedures, (e.g., EBR-II, FFTF).

12. Materials testing (e.g., $\mathrm{SiC}-\mathrm{SiC}$, other high temperature materials)

- Data handbook of essential thermomechanical, thermophysical properties

- Code case data for extended time ( $\sim 500,000$ hours $)$ older materials as well as new materials

- Corrosion testing in high-temperature lead $\left(>500^{\circ} \mathrm{C}\right)$ for high-performance lead fast reactor evolutions

- Analysis and testing of lead freezing consequences

- Access to Advanced Test Reactor and HFIR.

13. Fuel transient testing; TREAT start-up

- Fuel and cladding behavior tests.

14. Fuel performance testing and data

- Access to irradiation test facilities

- Industry is unified on the need for a U.S. fast-spectrum test reactor and their involvement is high right now.

15. Nuclear engineers; increase expertise in nuclear energy industry

- Continue and upgrade existing university programs by teaching in-depth courses in advanced reactors. Work to retain undergrads in the program through graduation.

- Public

- Showcase historical advances in nuclear energy; communicate fast reactor history

- Promote impact of nuclear energy for the future

- Increase internships in labs and industry. Provide financial assistance. 
16. Embedded staff between industry and national laboratories

- Bring in laboratory staff to fill the need for experienced engineers for industry.

- Some developers need training opportunities now to better understand technology needs and to determine what DOE/laboratory resources are available to meet their needs.

- Embedding industry staff at the national labs would be helpful. In addition, temporary assignments of national laboratory personnel to industry would be useful.

- The early stages of technology development provide the best opportunities for fruitful cooperation between industry and laboratory personnel. Opportunities should be created to promote such interactions.

17. Standardized contracting

- Current team of ANL, INL, and ORNL is working on this. Should have industry involved in this process. Commercial terms. Make it easier.

- Clarify in advanced the intellectual property (IP) expectations from DOE.

- Identify contracting mechanisms that could protect proprietary information and IP belonging to a private company or co-generated by the public-private partnership.

- Noted that at least one national laboratory has a visitor access request form with a blanket claim to IP generated during the on-site visit. Private companies with IP to protect are not likely to agree to a lab-site visit under such conditions. To implement GAIN, DOE contracting mechanisms and the people reviewing/implementing them need to have the latitude to make commonsense decisions which support, rather than inhibit, collaboration.

18. Cost of doing business at DOE laboratories

- If the process is hard, it adds to the private-sector cost of working with the DOE. Simplify the process

- GAIN will look into comparative rates to determine whether rates charged to the private sector are reasonable.

19. Start doing something now

- DOE-NE budget needs to increase to support future advanced reactor R\&D (build the program)

- Everything nuclear is long-term. Some certainty in budgets would be helpful

- Legislation is needed to raise nuclear to the level of other energy subsidies

- Industry should influence Congress to impact the budgets. Industry has a strong voice

- Turn around the negative publicity. Promote our clean energy goals

- Establish a National Energy Policy.

\section{Fast Reactor Workshop Conclusions}

A fast test reactor is being considered by DOE. Industry will have opportunities to provide requirements (i.e., loops, capacity, data, etc.) in the next year or so as the development process moves forward. 
Modeling and simulation is a cross-cutting need for advanced nuclear concepts. GAIN will communicate to industry on both NEAMS and CASL progress and capability, as well as other relevant efforts. A presentation will be prepared to facilitate communication. Training is available and easily scheduled. The suggestion of embedded experts to work on these tools will be seriously considered.

\section{Next Steps}

The participants proposed to form an industry-led Fast Reactor TWG, supported by the NEI ARWG, with EPRI and GAIN support. The Fast Reactor TWG will identify and resolve common development issues as well as a venue to advocate for fast reactor technology. The next meeting of participants will be as the newly-formed Fast Reactor TWG. Their first meeting is scheduled for September 7, 2016 at NEI offices to develop a draft working group structure and charter. The Fast Reactor TWG chair will be invited to participate in the GAIN IWG.

\section{Recommendations to DOE:}

- Provide access to intermediate-capability computing hardware (with computing power between that of modern supercomputers and widely available PC or workstation clusters).

- Resolve the difficulty of access to AT documents. An update will be provided at the next Fast Reactor TWG meeting.

- Complete the options and requirements assessment for a domestic fast spectrum test reactor. If the need and feasibility are validated, complete the mission need (Critical Decision, CD-0). 


\section{GAIN Management Team}

Rita Baranwal, GAIN Director

Doug Crawford, GAIN Deputy

Lori Braase, GAIN Coordinator

John Jackson, GAIN Technical Interface

Hussein Khalil, GAIN Integration Working Group Chair

Contact lori.braase@inl.gov for more information.

INL/EXT-16-39732

August 2016

Revision 1: March 24, 2017 